\title{
Revealed preference valuation of beach and river water quality in Wales
}

\author{
Paulo Rui Anciaes \\ University College London, United Kingdom
}

Accepted version of paper published in Journal of Environmental Economics and Policy, https://doi.org/10.1080/21606544.2020.1864778 (2021)

\begin{abstract}
This paper is a comprehensive valuation of water quality for outdoor recreation in Wales, considering all beaches and rivers in the country, and accounting for the value accrued to existing visits and generated from new visits. The values were aggregated for the population and mapped to show where the benefits of improving water quality are higher. We used a revealed preference method based on a linked random utility model explaining choice of beaches and rivers and monthly number of visits. Improving water quality of a beach from good to excellent has an estimated value of $£ 3.42$ per existing visit and leads to an average $54 \%$ increase in the number of visits, resulting in an overall value of $£ 269,445 /$ month. Improving water quality of a beach from sufficient/poor to good has a smaller value and impact on number of visits. Improving water quality of a river stretch to above bad/poor has a value of $£ 1.51$ per existing visit and leads to a $65 \%$ increase in the number of visits, resulting in an overall value of $£ 23,913 /$ month. Improving water flow has a higher value and impact on number of visits. We discuss how the assumptions made in the analysis might affect these results.
\end{abstract}

\section{Introduction}

Visiting rivers and beaches are two of the most popular outdoor activities around the world, accounting for many recreation trips every year (Jensen and Guthrie 2006, Bell et al. 2007). However, the number of trips that people make, and the benefit they derive from those trips, depends on water quality in the sites visited. For example, valuation studies have found that recreation is the main reason for people's willingness to pay for improved water quality (Söderqvist 1998). Water quality in rivers and beaches is currently threatened by pollution (Derraik 2002, Abu-Hilal and Khordagui 2007), water scarcity and droughts (Mosley 2015), climate change (Murdoch et al. 2000, Arheimer et al. 2005), fast growth of tourism (Almeida 
et al. 2007, Torres-Bejarano et al. 2018), and the encroachment of urban areas on coastlines and water bodies (Ouyang et al. 2006, Almeida et al. 2007). These threats can have a large negative impact on recreational uses of beaches and rivers (Toimil et al. 2018). Concerns about water quality have also led to actions at the national and international level. For example, the Water Framework Directive established a legislative framework for protecting and improving water resources in the European Union (EP/EC 2000).

These issues are highly relevant in Wales, one of the four countries in the United Kingdom, with 2,530 km of coastline and 7,450 km of rivers (Figure 1). Among the residents who made at least one outdoor visit within a year, $77 \%$ visited a beach and $67 \%$ visited a river (NRW 2015). Water quality is one of the main determinants of the choice of which beach to visit in Wales, among other characteristics, such as quality of sand, cleanliness, and safety (Tudor and Williams 2006). Water quality has improved during the last decades in areas that traditionally had intensive mining and heavy industries, but is still affected by diffuse water pollution from industrial sources and surface water drainage from populated areas and farms (NRW 2013).

Figure 1: Wales: beaches, rivers, and major urban areas

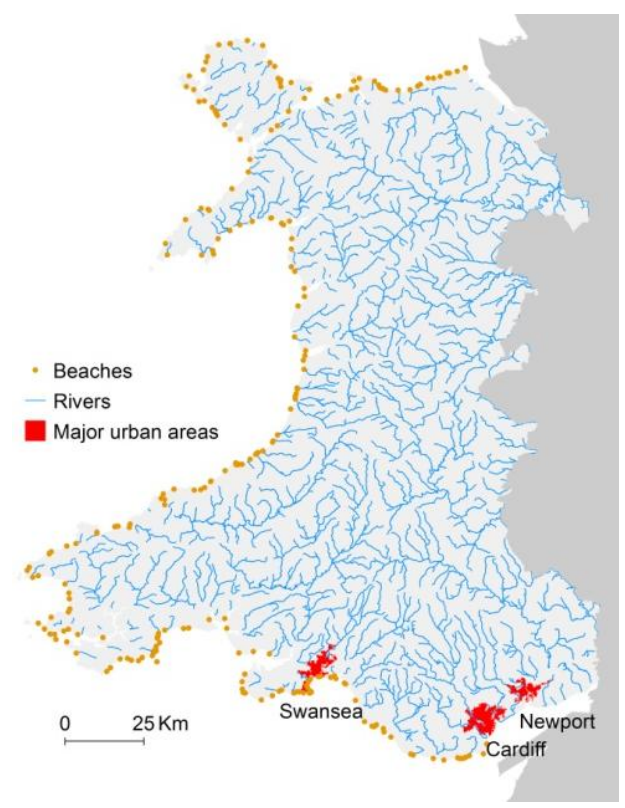

The definition and implementation of policies to improve water quality in beaches and rivers requires objective estimates of the value of water quality for recreational use, among other uses. This is useful to compare the benefits of improving water quality in different beaches and rivers, and then to compare these benefits with the costs of the policies. Previous studies have quantified the value of water quality using the two main methods for the economic valuation of non-market goods: stated preference and revealed preference. 
However, few studies have considered the value generated by new trips to beaches and rivers and even fewer have aggregated the values at the country level or mapped how the value varies within the country.

This paper analyses the value of potential improvements in beach and river water quality in Wales, using a revealed preference method (travel cost) within a linked random utility model that explains the choice of the beaches/rivers visited and the frequency of visits. We matched data from a national survey of outdoor recreational visits with data on all beaches and rivers in Wales. We then calculated the impact of changes in water quality on the value for existing and new visits and on the number of visits, aggregating and mapping the values at the county level.

The rest of the paper is split into seven sections. Section 2 reviews previous studies valuing beach and river water quality. Sections 3 and 4 describe data and methods. Sections 5 and 6 present the findings for beach water quality and river water quality, respectively. Section 7 discusses the assumptions used in the analysis and Section 8 concludes the paper.

\section{Literature review}

The value of beach and river water quality for recreational uses has been estimated with the standard methods of economic valuation, which fall broadly into two categories: stated preference and revealed preference.

Stated preference methods use surveys to capture preferences about different aspects of the recreational use of beaches and rivers and estimate the willingness to pay for improvements in those aspects. Contingent valuation is a relatively simple stated preference method that was used in many early studies in this field. This method is based on surveys where participants are asked directly for their willingness to pay in a bid game where values are gradually increased or decreased. Examples of the use of contingent valuation include, for beach/coastal water quality, Bockstael et al. (1989), Georgiou et al. (1998), and Machado and Mourato (2002), and for river water quality, Green and Tunstall (1991), Carson and Mitchell (1993) and Magat et al. (2000). As in other fields, the method is prone to generate protest answers, with many participants stating they are not willing to pay any amount.

Choice experiments are a more complex stated preference method, estimating the value of various aspects of the recreational use of beaches and rivers, including water quality. Survey participants are asked to choose among hypothetical scenarios for the beaches and rivers visited, each with a different set of characteristics and an associated monetary cost (e.g. water 
bill, travel cost, fees to use sites). The method has three strengths. First, it can be used to estimate more comprehensive preference trade-offs between water quality improvements and increase in costs than those obtained with contingent valuation - for example by considering improvements in different sites at different times (Glenk et al. 2011). Second, it can capture trade-offs between the use value of water quality for recreation and the non-use value (e.g. biodiversity) (Eggert and Olsson 2009, Pakalniete et al. 2017). Third, it allows for the estimation of trade-offs between water quality and other characteristics of beaches and rivers. For example, studies on beaches found that users value characteristics such as the availability of facilities (e.g. showers, restrooms), information, cleanliness, presence of a lifeguard, sand quality, lack of pollution and debris, safety, and congestion (EFTEC 2002, Meyerhoff et al. 2008, Beharry-Borg and Scarpa 2010, Hynes et al. 2013, Penn et al. 2015). Studies on rivers found that users value the restoration of water flows and riverbanks, lack of debris and pollution, and reduced flood risk (Morrison and Bennett 2004, Hanley et al. 2006, Perni et al. 2012, Brouwer et al. 2016).

The problem of stated preference methods is the hypothetical nature of the scenarios presented to participants, which tend to lead to an overestimation of willingness to pay. Revealed preference methods solve that problem by modelling observed behaviour, i.e. choices made in the real world, thus accounting for behavioural constraints that are not usually considered in stated preference studies. One possibility is hedonic pricing, i.e. models relating property prices with indicators of water quality in beaches or rivers in the surrounding areas (Leggett and Bockstael 2000, Poor et al. 2007, Artell 2014, Hjerppe et al. 2017). These models can produce powerful results - when they can be estimated. In practice, it is difficult to disentangle the value of water quality from the value of the many other aspects influencing property prices.

The travel cost method is another common revealed preference method. It assumes that the travel cost to visit a site (beach or river) is an indicator of the price of accessing that site. The number of trips that individuals make to different sites, or to the same site at different moments in time, can be modelled as a function of travel cost and various site-specific variables. Willingness to pay can then be derived from the estimated model. Lew and Larson (2005) used this method to estimate how the choice of which beach to visit depends on water quality and other beach characteristics (lifeguards, activity management, and availability of parking) in a region in the USA. Two studies in Finland estimated the value of water quality 
for swimming, fishing, and boating trips (Vesterinen et al. 2010) and for trips to second homes (Huhtala and Lankia 2012).

What was seldom acknowledged in previous studies was that improving water quality adds not only to the value of existing trips, but also generates new value, from new trips. This aspect can be integrated in the analysis by adding a "contingent behaviour" question in surveys, asking how many trips participants would make for given levels of water quality (Loomis 2002, Hanley et al. 2003, Lankia et al. 2019). An alternative method is to link the number of trips to the utility that can be derived from the available sites. Bockstael et al. (1987) used this method within a model linking two components. A site choice model explains choices of sites as a function of site characteristics and travel cost to access it. A participation model explains number of visits to all sites as a function of individual characteristics and an indicator of the maximum expected utility each individual gains from all sites. This indicator is known as the inclusive value or log sum and can be derived from the site choice model (Williams 1977, Small and Rosen 1981). The linked model thus accounts for site substitution effects and changes in the number of visits to all sites. Johnstone and Markandya (2006) and Anciaes et al. (2020) used this model to value various aspects of river water quality in the context of angling trips in England.

In the present paper, we use the Bockstael et al. (1987) method to value beach and river water quality, considering the value for existing trips and new trips. Our contribution to the literature is twofold. First, we use the method to value both beach and river water quality, for all recreational uses. As noted above, the studies of Johnstone and Markandya (2006) and Anciaes et al. (2020) were limited to angling trips to rivers. Second, we use the method to estimate values at the national level, based on the behaviour of a nationally representative sample, aggregated for the whole population of Wales, and mapped to show where potential benefits of improving water quality are higher.

\section{Data and variables}

\subsection{Visits}

We used data on visits to beaches and rivers, extracted from the Welsh Outdoor Recreation Survey (WORS) 2014-2015. This is a survey of a representative sample of 5,995 Welsh residents, ran by Natural Resources Wales. Most of the survey data is openly available, including participant characteristics (demographic, socio-economic, and attitudinal), the number of outdoor trips for recreation in the last four weeks, and details on the most recent 
trip. Data on the home location of each participant (postcode) and location of the main site visited in the last trip was provided to the author by Natural Resources Wales. The data also includes a participant weight (representative of the Welsh adult population) and a visit weight (representative of the visits taken by that population).

The monthly number of outdoor visits was collected in the survey in a closed-ended question with nine possible intervals of values. We took the mid-point of all intervals and the lower end of the last interval (101+). We then estimated the monthly number of visits to beaches, sea, or coastline locations as the number of all outdoor visits made in the last four weeks, if the participant visited those types of sites in their last visit. Similarly, the monthly number of visits to rivers, lakes, or canals was the number of all outdoor visits made in the last four weeks, if the participant stated they visited those types of sites in their last visit. In Section 7, we discuss the implications of this and other assumptions.

\subsection{Beach and river characteristics}

The data on beach characteristics was scraped from the British Beaches Info website (https://britishbeaches.uk) in November 2017. The data contains the location of 225 beaches in Wales and information on water quality, as assessed by Natural Resources Wales in the summer of 2017. Water quality is classified annually in Wales as excellent, good, sufficient, or poor, based on four years of analyses (during the summer bathing season) of samples for two types of bacteria: Escherichia coli (E. coli) and intestinal enterococci. The British Beaches Info website also contains information on other beach characteristics, including available facilities (e.g. showers), beach features (e.g. promenade), types of sea life (e.g. seals), and activities (e.g. windsurfing). Table A1 in Appendix lists all characteristics. Descriptive statistics on all variables extracted from the data will be presented in Section 5.1.

The data on river characteristics comes from a spatial dataset including all water bodies managed by Natural Resources Wales under the Water Framework Directive. We retrieved the data in November 2017 from the Natural Resources Wales website. The data contains the location and shape of 737 river stretches and information on water quality. Water quality is classified using the Water Framework Directive classification scheme (good, high, moderate, poor, or bad), based on chemical and ecological conditions (EP/EC 2000, Quevauviller et al. 2008). The data also contains the results of a flow test (pass or fail), and whether the river stretch is a highly modified water body. We calculated two additional variables using a GIS (geographic information system): the proportion of the area around $200 \mathrm{~m}$ of the river stretch 
that is green (an indicator of the recreational value of the water body) and the proportion of the same area that is urban (an indicator of the accessibility of the site). The data on green spaces and urban areas was extracted from the UK Ordnance Survey Open Green Space dataset and Ordnance Survey Geography Open Data, respectively. Descriptive statistics will be presented in Section 6.1.

We estimated travel distance on the road network from the home location of the WORS participants to all beaches and rivers in the British Beaches and Water Framework Directive datasets. The home location was identified as the centroid of the postcode area stated by participants. We built a bespoke model of the Welsh road network from line data of Great Britain's road network (extracted from the Ordnance Survey Open Roads dataset). We assigned a travel speed of $110 \mathrm{~km} / \mathrm{h}$ to motorways; $110 \mathrm{~km} / \mathrm{h}$ and $75 \mathrm{~km} / \mathrm{h}$ to dual-carriageway roads in non-built-up and built-up areas, respectively; and $50 \mathrm{~km} / \mathrm{h}$ and $40 \mathrm{~km} / \mathrm{h}$ to other roads in non-built-up and built-up areas, respectively. We then estimated the fastest routes from the home location of all WORS participants to all beaches and rivers, using ArcGIS 10.4 Network Analyst.

The car travel cost of a return trip from homes to each beach and river was then calculated by multiplying the return trip distance by a unit cost of $£ 0.368 / \mathrm{mile}$. This unit cost is the sum of two components. The first component is the out-of-pocket cost (£0.134/mile). This is the average of the petrol and diesel costs, as given by the Automobile Association in 2014 (https://www.theaa.com). The second component is the opportunity cost of the time spent travelling ( $£ 0.234 / \mathrm{mile})$. This is the ratio between $£ 11.21 /$ hour (the value of non-work and non-commuting travel time as given by DFT (2015a), and 48mph (the average speed on single carriageway roads outside urban areas, as given by DFT (2015b)).

\subsection{Matching visits to sites}

We then matched the locations of the beaches and rivers visited by the WORS participants and the locations of beaches and rivers in the British Beaches and Water Framework Directive datasets. The match did not include WORS participants who: 1) made no visits to beaches/rivers; 2) did not provide home location; 3) made visits to beaches/rivers that were not the main site of the visit (and so were not asked in the survey about location of those beaches/rivers); 4) did not provide location of the visit; or 5) made visits to locations outside Wales. After excluding these participants, 633 visits to beaches and 200 visits to rivers were retained. 
We then identified the visited beaches and rivers of the retained participants as the nearest beach and river in the British Beaches and Water Framework Directive datasets. Visits where the nearest water body was a lake or canal, not a river, were excluded. We assumed that the sites that could be matched to a beach are indeed a beach and not sea or coastline feature. Visits more than $800 \mathrm{~m}$ straight line distance from the nearest beach or river were excluded. 416 visits to beaches and 105 visits to rivers were matched.

\section{Methods}

\subsection{Overview}

We used the linked random utility model introduced by Bockstael et al. (1987). The model has two components. The site choice model explains the WORS participants' choice of which beach or river to visit as a function of the beach/river characteristics and the estimated travel cost. The participation model explains the number of visits over a month as a function of the participants' characteristics and the inclusive value derived from the site choice model. The expectation is that an improvement in water quality at a site increases the utility of that site in the site choice model, which then increases, via the inclusive value, the number of visits predicted in the participation model.

\subsection{Site choice model}

We used a conditional logit specification for the site choice model (McFadden 1974). The utility $U_{i j}$ for individual $i$ visiting site $j$ on a given occasion depends on the travel cost to the site $\left(\mathrm{c}_{i j}\right)$, the characteristics of the site $\left(x_{j}\right)$, and a random error term $\left(\varepsilon_{i j}\right)$ accounting for unobserved factors. The vectors $\delta$ and $\tau$ are parameters to be estimated.

$$
U_{i j}=\delta c_{i j}+\tau x_{j}+\varepsilon_{i j}
$$

If the error terms are independently and identically distributed with a Type I Extreme Value distribution, the probability $P_{i j}$ that individual $i$ chooses site $j$, given all available sites $l$, can be expressed as in the equation (2) below (McFadden 1978). The parameters $\delta$ and $\lambda$ can be estimated by maximum likelihood.

$$
P_{i j}=\exp \left(\delta c_{i j}+\lambda x_{j}\right) / \sum_{l} \exp \left(\delta c_{i l}+\lambda x_{l}\right)
$$

The inclusive value $V_{i}$ of individual $i$ is given by the natural logarithm of the denominator of equation (2):

$$
V_{i}=\ln \left(\sum_{l} \exp \left(\delta c_{i l}+\lambda x_{l}\right)\right)
$$


The beach and river choice models included 1,881 and 1,727 WORS participants respectively, i.e. participants who provided home location and who made at least one visit to a beach/river in the last month. Participants with missing location for the visit were included, because they attach utility to the visits and so their inclusive value can be calculated. The models were estimated in an expanded dataset containing multiple records per participant, i.e. one record for each beach/river, plus a record for sites not visited as the main site of the trip and a record for sites with no location information or not matched to a site in the beaches or rivers datasets. These two records are identified in the model by dummy variables.

The dependent variable of the models is a dummy variable equal to 1 if the beach/river was visited and 0 otherwise. The explanatory variables of the beach choice model were the return trip travel cost to the beach; dummy variables for beach water quality; and the number of different facilities, beach features, types of sea life, and activities. The explanatory variables of the river choice model were the return trip travel cost; dummy variables for river water quality; and dummy variables for other river characteristics (flow, highly modified water body status, and proportions of the areas within $200 \mathrm{~m}$ of the river that is green and urban). Both models were weighted using the WORS visit weight.

\subsection{Participation model}

We used a negative binomial specification for the participation model, following Hynes et al. (2015) and Breen et al. (2018). This specification accounts for the high proportion of individuals who made zero visits and for unobserved heterogeneity, i.e. differences across individuals that are not captured by the explanatory variables.

Equation (4) gives the distribution of the number of visits $T_{i}$ made by individual $i$ over a month. Equation (5) gives the conditional mean $\left(\mu_{i} \eta_{i}\right)$ of the number of visits, which depends on the characteristics of the individual $\left(r_{i}\right)$, the inclusive value for that individual $\left(V_{i}\right)$, and a random error term $\varepsilon_{i}$ accounting for unobserved factors uncorrelated with the characteristics of the individual. The vector $\xi$ and $\theta$ are parameters to be estimated.

$$
\begin{gathered}
f\left(T_{i} \mid r_{i}, \eta_{i}\right)=\left(\exp \left(-\mu_{i} \eta_{i}\right)^{*}\left(\mu_{i} \eta_{i}\right)^{T i}\right) / T_{i} ! \\
E\left(T_{i} \mid r_{i}, \eta_{i}\right)=\mu_{i} \eta_{i}=\exp \left(\theta r_{i}+\xi V_{i+} \varepsilon_{i}\right), \text { where } \eta_{i=} \exp \left(\varepsilon_{i}\right)
\end{gathered}
$$

If $\eta_{i}$ follows a gamma distribution with $E\left(\eta_{i}\right)=1$ and $\operatorname{Var}\left(\eta_{i}\right)=1 / z_{i}$, the conditional variance of the number of visits is:

$$
\operatorname{Var}\left(T_{i} \mid r_{i}\right)=\mu_{i}\left(1+\mu_{i} / z_{i}\right)
$$

If $z_{i}=z=1 / \sigma$ for all individuals and $\sigma>0$, equation (6) can be rewritten as 


$$
\operatorname{Var}\left(T_{i} \mid r_{i}\right)=\mu_{i}\left(1+\mu_{i} / z\right)=\mu_{i}\left(1+\sigma \mu_{i}\right)
$$

Since $\mu_{i}$ and $z$ are positive, the conditional variance is greater than the conditional mean. $\sigma$ is an indicator of dispersion, as higher values for $\sigma$ result in a higher conditional variance.

The model includes all 5,995 WORS participants, as the model estimates the influence of demographic variables on the number of visits, even when participants are missing an inclusive value.

The model consists of a pair of equations predicting two outcomes: the probability that the individual made zero visits to a beach/river in the last month, and the number of visits made during that month. The explanatory variables are the inclusive value derived from the beach/river choice model, a dummy variable for participants with no inclusive value because they were not included in the site choice model, and dummy variables for the characteristics of the participant. The model was weighted using the WORS participant weight. Variables not significant at the $10 \%$ level were excluded from the final model. However, the inclusive value was always kept in the model.

\subsection{Value}

The per-visit value for existing visits for changes in water quality in an unspecified beach/river was estimated from the site choice model as the ratio of the coefficient of the variables representing those characteristics and the coefficient of travel cost. Confidence intervals were calculated using the Krinsky Robb parametric bootstrap method (Krinsky and Robb 1986).

We then used the site choice model to estimate the inclusive value, which was entered in the participation model to estimate the total number of trips to all beaches/rivers. This was done for the current situation and for hypothetical scenarios of improvements of water quality or other characteristics in each of the beaches/rivers separately. The number of visits was then aggregated for the population using the WORS participant weight.

In each scenario, the benefit $B_{i}^{J}$ for individual $i$ of improving beach/river $j$ was estimated as the product of the predicted number of visits $T_{i}^{J}$ and the inclusive value $V_{i}^{J}$ after the improvement, subtracted by the same product before the improvement $\left(T_{i} V_{i}\right)$, and divided by the cost coefficient of the site choice model $(\delta)$.

$$
B_{i}^{J}=\left(T_{i}^{J} V_{i}^{J}-V_{i} T_{i}\right) / \delta
$$

We then calculated the following three outcomes of separate improvements in each beach/river, where $\mathrm{n}$ is the number of beaches/rivers: 
- Average $\%$ change in the number of visits to the improved beach/river: $100^{*} \sum_{J}\left(\sum_{i}\right.$ $\left.T_{i, j}{ }^{J} \sum_{i} T_{i, j}-1\right) / n$

- Average value for existing and new visits, as a ratio of the existing number of visits: $\sum_{J}\left(\sum_{i} B_{i}^{J} / \sum_{i} T_{i}\right) / n$

- Average value per month for existing and new visits: $\sum_{i, J} B_{i}^{J} / n$

\section{Beach water quality}

\subsection{Beach choice model}

Table 1 shows descriptive statistics of the explanatory variables in the beach choice model, for all beaches in the British beaches dataset and for beaches visited by WORS participants. Water quality was not measured in $56 \%$ of the beaches. $36 \%$ of the beaches have excellent water quality, $5 \%$ have good quality and $2 \%$ have sufficient or poor water quality. On average, Welsh beaches have almost half (2.67) of the six possible types of facilities, but a small number of beach features, types of sea life, and activities, compared with the maximum possible number. On average, the set of visited beaches have smaller travel costs, better water quality, and more facilities, beach features, and activities than the set of all beaches, which suggests that these factors influence the choice of beaches.

Table 1: Beach choice model: explanatory variables

\begin{tabular}{|c|c|c|c|c|c|}
\hline & \multirow{2}{*}{$\begin{array}{c}\text { Maximum } \\
\text { possible }\end{array}$} & \multicolumn{2}{|c|}{ Beaches } & \multicolumn{2}{|c|}{ Visits } \\
\hline & & Mean & $\begin{array}{l}\text { Standard } \\
\text { deviation }\end{array}$ & Mean & $\begin{array}{l}\text { Standard } \\
\text { deviation }\end{array}$ \\
\hline Travel cost (return trip) & - & $£ 72.1$ & $£ 40.2$ & $£ 11.4$ & $£ 18.5$ \\
\hline \multicolumn{6}{|l|}{ Beach water quality } \\
\hline Excellent & - & 0.36 & - & 0.51 & - \\
\hline Good & - & 0.05 & - & 0.07 & - \\
\hline Sufficient or poor & - & 0.02 & - & 0.01 & - \\
\hline Not measured & - & 0.56 & - & 0.41 & - \\
\hline \multicolumn{6}{|l|}{ Other beach characteristics } \\
\hline Number of facilities & 6 & 2.67 & 1.63 & 3.46 & 1.41 \\
\hline Number of beach features & 25 & 1.02 & 1.19 & 1.32 & 1.35 \\
\hline Number of sea life & 4 & 0.20 & 0.63 & 0.12 & 0.50 \\
\hline Number of activities & 24 & 4.25 & 1.95 & 4.83 & 1.94 \\
\hline Number of observations & & \multicolumn{2}{|c|}{225 beaches } & \multicolumn{2}{|c|}{416 visits } \\
\hline
\end{tabular}

Table 2 shows the estimated beach choice model. As expected, participants prefer to visit beaches with excellent water quality, following by those with good water quality, and those with sufficient or poor water quality. Beaches where the water quality was not measured are 
less attractive that those where water quality is measured, even when the water quality is Sufficient or Poor. Participants also prefer visiting beaches with lower travel costs and with more facilities, beach features, types of sea life, and activities.

Table 2: Beach choice model

\begin{tabular}{|c|c|c|c|}
\hline Variable & Coefficient & $\begin{array}{c}\text { Standard } \\
\text { error }\end{array}$ & p value \\
\hline Travel cost & -0.123 & 0.001 & $<0.001$ \\
\hline \multicolumn{4}{|l|}{ Water quality } \\
\hline Excellent & 0.536 & 0.014 & $<0.001^{* * * * *}$ \\
\hline Good & 0.115 & 0.026 & $<0.001^{* * * * *}$ \\
\hline Sufficient or Poor & 0.098 & 0.062 & $0.096^{*}$ \\
\hline \multicolumn{4}{|l|}{ Other beach characteristics } \\
\hline Number of facilities & 0.246 & 0.005 & $<0.001^{* * * *}$ \\
\hline Number of beach features & 0.036 & 0.005 & $<0.001^{* * * * *}$ \\
\hline Number of sea life & 0.046 & 0.013 & $<0.001^{* * * * *}$ \\
\hline Number of activities & 0.044 & 0.003 & $<0.001^{* * * * *}$ \\
\hline \multicolumn{4}{|l|}{ Beaches with missing location } \\
\hline Beaches with no location or not matched & 3.610 & 0.021 & $<0.001^{* * * * *}$ \\
\hline Beaches not visited as the main site in the trip & 4.236 & 0.020 & $<0.001^{* * * * *}$ \\
\hline Number of participants & & 1,881 & \\
\hline Number of observations & & 428,868 & \\
\hline Pseudo $\mathbf{R}^{2}$ & & 0.685 & \\
\hline
\end{tabular}

Notes: Significance levels: ${ }^{*} 10 \%,{ }^{* * * *} 0.1 \%$. Omitted category: water quality not measured.

We calculated the inclusive value for each individual, using the model coefficients and the characteristics of all beaches and travel costs to access them. We then interpolated these values to obtain a surface covering Wales (Figure 2). As expected, coastal areas have higher inclusive values and areas inland have lower values. The highest values are in the southwest coast. 
Figure 2: Beaches: inclusive values

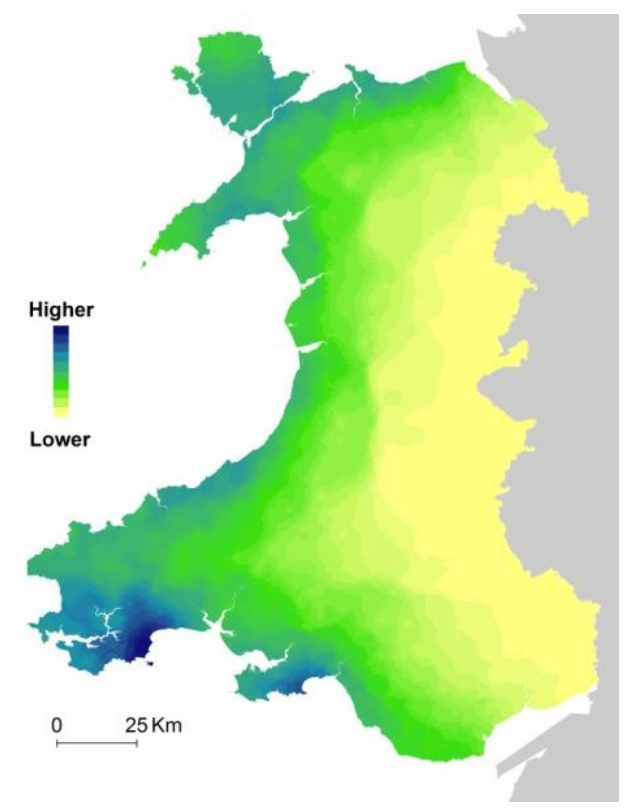

\subsection{Participation model}

Table 3 shows descriptive statistics of the explanatory variables of the participation model. The third column shows the proportion of each group in the population. The demographic characteristics of the sample are consistent with those of the Welsh adult population: the majority live in urban areas, have medium qualifications, and own a car.

The table does not report statistics on variables that were calculated from WORS but were not used in the final participation model because they were insignificant (e.g. gender, ethnic group, employment status, index of deprivation, type of job, access to a bicycle, and environmental concern) or had too many missing values (e.g. household income, which had $27 \%$ of missing values). 
Table 3: Beaches: participation model variables

\begin{tabular}{|c|c|c|c|}
\hline & \multicolumn{2}{|c|}{ Sample } & \multirow{2}{*}{ Population } \\
\hline & Mean & $\begin{array}{l}\text { Standard } \\
\text { Deviation }\end{array}$ & \\
\hline Number of visits & 4.230 & 10.670 & - \\
\hline Number of visits $=0$ & 0.702 & - & - \\
\hline \multicolumn{4}{|l|}{ Inclusive value } \\
\hline Value & 4.824 & 0.128 & - \\
\hline Value $=$ missing & 0.033 & - & - \\
\hline \multicolumn{4}{|l|}{$\overline{\text { Participant characteristics }}$} \\
\hline Age: $16-24$ & 0.150 & - & 0.149 \\
\hline Age: $25-44$ & 0.300 & - & 0.302 \\
\hline Age: 45-64 & 0.330 & - & 0.325 \\
\hline Age: $65-74$ & 0.120 & - & 0.120 \\
\hline Age: $>75$ & 0.100 & - & 0.104 \\
\hline Type of area: urban & 0.600 & - & 0.672 \\
\hline Type of area: town fringe & 0.200 & - & 0.158 \\
\hline Type of area: rural & 0.196 & - & 0.328 \\
\hline Qualifications: high & 0.273 & - & 0.245 \\
\hline Qualifications: medium & 0.591 & - & 0.496 \\
\hline Qualifications: low & 0.136 & - & 0.259 \\
\hline Illness or disability limiting activities & 0.214 & - & 0.227 \\
\hline Carer & 0.202 & - & 0.121 \\
\hline Have access to a car/van & 0.836 & - & 0.771 \\
\hline Owns/cares for a dog & 0.360 & - & 0.291 \\
\hline
\end{tabular}

Note: Number of observations=5,995. Population data source: Census 2001, except "owns/cares for a dog": National Survey Wales 2014/2015. Rural: village, hamlet, isolated dwelling. Low qualifications: never went to school; not finished school; or no qualifications. High qualifications: higher education/professional or vocational equivalent, or higher.

Table 4 shows the estimated model. As expected, individuals with higher inclusive value make more trips. Individuals who live in rural areas, have high qualifications, are carers, and own a dog, also make more trips. Individuals with lower inclusive value, who are aged 16-24 or above 75 , live on the fringes of towns or in rural areas, have low qualifications, have a disability, are not carers, and do not have access to a car/van have a higher probability of making no trips to a beach over a month. The dispersion parameter is significant, which shows that the dependent variable is overdispersed and is better modelled using a negative binomial model than a Poisson model. 
Table 4: Beaches: participation model

\begin{tabular}{|c|c|c|c|}
\hline & Coefficient & $\begin{array}{c}\text { Standard } \\
\text { error }\end{array}$ & p-value \\
\hline \multicolumn{4}{|l|}{ Number of visits } \\
\hline \multicolumn{4}{|l|}{ Inclusive value } \\
\hline Value & 0.830 & 0.278 & $0.003^{* * *}$ \\
\hline Missing inclusive value & 4.087 & 1.376 & $0.003^{* * *}$ \\
\hline \multicolumn{4}{|l|}{ Participant characteristics } \\
\hline Type of area: rural & 0.173 & 0.087 & $0.045^{* *}$ \\
\hline Qualifications: high & 0.165 & 0.076 & $0.030^{* *}$ \\
\hline Carer & 0.139 & 0.084 & $0.098^{*}$ \\
\hline Owns a dog & 0.541 & 0.073 & $0.000^{* * *}$ \\
\hline Constant & -1.840 & 1.359 & 0.176 \\
\hline \multicolumn{4}{|l|}{ Probability of zero visits } \\
\hline \multicolumn{4}{|l|}{ Inclusive value } \\
\hline Value & -6.314 & 0.410 & $0.000^{* * * *}$ \\
\hline Missing inclusive value & -30.370 & 2.002 & $0.000^{* * * * *}$ \\
\hline \multicolumn{4}{|l|}{ Participant characteristics } \\
\hline Age: $16-24$ & 0.819 & 0.151 & $0.000^{* * * *}$ \\
\hline Age: $>75$ & 0.483 & 0.019 & $0.012^{* *}$ \\
\hline Type of area: town fringe & 0.347 & 0.131 & $0.008^{* * *}$ \\
\hline Type of area: rural & 0.245 & 0.127 & $0.055^{*}$ \\
\hline Qualifications: low & 0.486 & 0.164 & $0.003^{* * *}$ \\
\hline Illness or disability limiting activities & 0.365 & 0.130 & $0.005^{* * *}$ \\
\hline Carer & -0.228 & 0.121 & $0.058^{*}$ \\
\hline Have access to car/van & -0.448 & 0.151 & $0.003^{* * *}$ \\
\hline Constant & 31.345 & 1.983 & $0.000^{* * * * * *}$ \\
\hline Dispersion parameter & 0.839 & 0.061 & $0.015^{* *}$ \\
\hline Number of observations & & 5995 & \\
\hline Number of zero observations & & 4062 & \\
\hline
\end{tabular}

Notes: Significance levels: ${ }^{*} 10 \%,{ }^{* *} 5 \%,{ }^{* * *} 1 \%,{ }^{* * * *} 0.1 \%$. Omitted categories: age $25-74$, urban areas, high or medium qualifications, no limiting disability, not a carer, does not own a dog, does not have access to a car/van.

\subsection{Value}

Table 5 shows the value of changes in water quality and other beach characteristics for existing visits and its $95 \%$ confidence interval, the average impact on the number of visits, and the average value for all visits (existing and new).

Improvements in water quality from good to excellent in a given beach have a value of $£ 3.42$ for existing visits and lead, on average, to a $54 \%$ increase in the number of visits to that beach. The average value for all visits (existing and new) is $£ 4.33$ (as a ratio of existing visits). This represents a total value of $£ 269,445$ per month. Improvements in water quality from sufficient/poor to good have a much smaller impact on number of visits (2\%) and value ( $£ 0.14 /$ existing visit and $£ 2,744 /$ month in total). Improvements in water quality to excellent in beaches where the water quality is currently not measured leads to an increase of $72 \%$ in number of visits and a value of $£ 5.92 /$ existing visit and $£ 205,499 /$ month in total. Improvements to good or sufficient have a much smaller impact and value. 
Table 5: Value and impact on visits of improvements in water quality and other beach characteristics

\begin{tabular}{|c|c|c|c|c|c|}
\hline \multirow{2}{*}{$\begin{array}{l}\text { Type of improvement } \\
\text { Type of change }\end{array}$} & \multirow{2}{*}{\multicolumn{2}{|c|}{$\begin{array}{c}\text { In an } \\
\text { unspecified beach } \\
\begin{array}{c}\text { Value for } \\
\text { existing visits }\end{array} \\
\end{array}$}} & \multicolumn{3}{|c|}{$\begin{array}{c}\text { Separate improvements } \\
\text { in each beach } \\
\end{array}$} \\
\hline & & & $\begin{array}{l}\text { Average change } \\
\text { in visits }\end{array}$ & $\begin{array}{r}\text { Averag } \\
\text { for existing a }\end{array}$ & $\begin{array}{l}\text { alue, } \\
\text { new visits }\end{array}$ \\
\hline Unit & $\begin{array}{r}\text { Per e } \\
\quad(\mathrm{c} \\
\text { confic }\end{array}$ & $\begin{array}{l}\text { isting visit } \\
\text { ntral and } \\
\text { nce interval) }\end{array}$ & $\%$ & $\begin{array}{l}\text { Per existing } \\
\text { visit }\end{array}$ & $\begin{array}{l}\text { Per } \\
\text { month }\end{array}$ \\
\hline \multicolumn{6}{|l|}{ Water quality } \\
\hline Good $\rightarrow$ Excellent & $£ 3.42$ & $(3.01,3.82)$ & $54 \%$ & $£ 4.33$ & $£ 269,445$ \\
\hline Sufficient/Poor $\rightarrow$ Excellent & $£ 3.56$ & $(2.57,4.54)$ & $56 \%$ & $£ 4.56$ & $£ 87,411$ \\
\hline Sufficient/Poor $\rightarrow$ Good & $£ 0.14$ & $(-0.90,1.19)$ & $2 \%$ & $£ 0.14$ & $£ 2,744$ \\
\hline Not measured $\rightarrow$ Excellent & $£ 4.35$ & $(4.13,4.57)$ & $72 \%$ & $£ 5.92$ & $£ 205,499$ \\
\hline Not measured $\rightarrow$ Good & $£ 0.93$ & $(0.53,1.34)$ & $12 \%$ & $£ 0.99$ & $£ 34,371$ \\
\hline Not measured $\rightarrow$ Sufficient & $£ 0.79$ & $(-0.19,1.78)$ & $10 \%$ & $£ 0.83$ & $£ 28,879$ \\
\hline \multicolumn{6}{|l|}{ Other site characteristics } \\
\hline 1 extra facility & $£ 2.00$ & $(1.92,2.07)$ & $29 \%$ & $£ 2.28$ & $£ 106,921$ \\
\hline 1 extra beach feature & $£ 0.30$ & $(0.22,0.37)$ & $4 \%$ & $£ 0.30$ & $£ 14,130$ \\
\hline 1 extra sea life & $£ 0.37$ & $(0.17,0.58)$ & $5 \%$ & $£ 0.38$ & $£ 17,883$ \\
\hline 1 extra activity & $£ 0.36$ & $(0.31,0.41)$ & $5 \%$ & $£ 0.36$ & $£ 17,045$ \\
\hline
\end{tabular}

Figure 3 shows the average value per month of separate improvements in each beach to achieve excellent water status, i.e. the values in the last column of Table 5. The map on the left shows the values in beaches where the water quality is currently measured, i.e. beaches where the water quality would improve from sufficient/poor or good to excellent. The map on the right shows the values in beaches where the water quality is not currently measured, i.e. beaches where the water quality would improve from unknown water quality to excellent. In both cases, the highest values are in the South coast, especially near Swansea (the second largest urban centre in Wales), followed by the North Coast. The values are smaller in the West Coast, which is explained both because of the remoteness of this area (attractive fewer visits) and because many beaches in that area already have excellent water quality. 
Figure 3: Value of improvements to excellent beach water quality ( $($ /month)
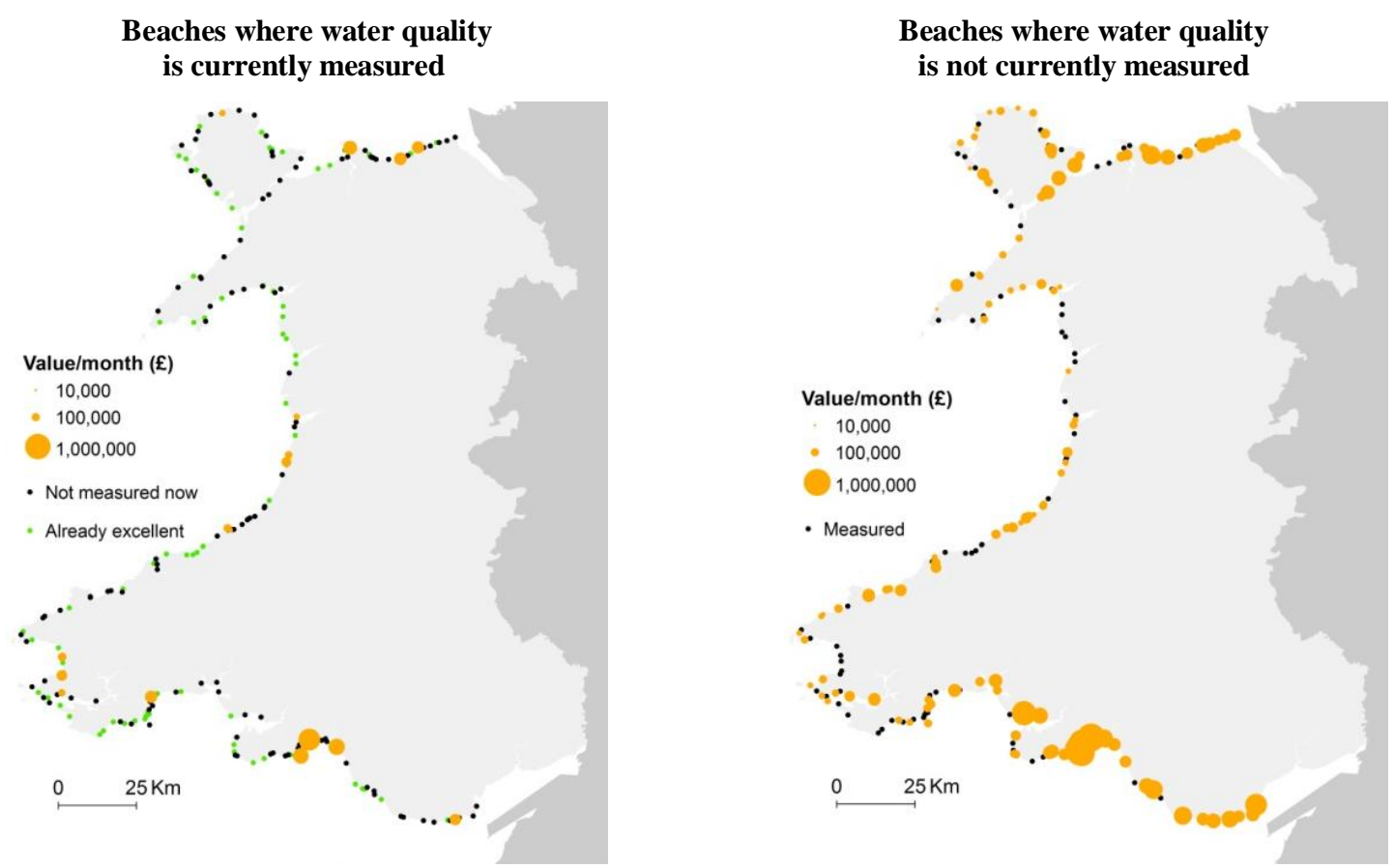

\section{River water quality}

\subsection{River choice model}

Table 6 shows descriptive statistics of the explanatory variables in the river choice model, for all rivers and for rivers visited by WORS participants. 39\% of the rivers in Wales have good or high water quality, $53 \%$ have moderate quality, and $8 \%$ have poor quality. $3 \%$ of rivers failed the water flow test and $13 \%$ were classified as heavily modified water bodies. Both spatial variables have a small mean but a high standard deviation as a proportion of the mean. The set of visited rivers have smaller travel costs; higher proportion of rivers that have with moderate water quality and are highly modified; and higher proportions of green and urban areas with $200 \mathrm{~m}$ of the rivers. 
Table 6: River choice model: explanatory variables

\begin{tabular}{lcccccc}
\hline & \multicolumn{2}{c}{ Rivers } & & \multicolumn{2}{c}{ Visits } \\
\cline { 2 - 3 } \cline { 5 - 6 } & Mean & $\begin{array}{c}\text { Standard } \\
\text { deviation }\end{array}$ & & Mean & $\begin{array}{c}\text { Standard } \\
\text { deviation }\end{array}$ \\
\hline Travel cost (return trip) & $£ 63.4$ & $£ 33.4$ & & $£ 3.9$ & $£ 7.7$ \\
\hline $\begin{array}{l}\text { Overall ecological status water quality } \\
\quad \text { Good or High }\end{array}$ & 0.39 & & & & 0.21 & - \\
$\quad$ Moderate & 0.53 & - & & 0.74 & - \\
$\quad$ Poor or Bad & 0.08 & - & & 0.06 & - \\
\hline Other river characteristics & & & & & \\
$\quad$ Flow test: fail & 0.03 & - & & 0.04 & - \\
$\quad$ Highly modified water body & 0.13 & - & & 0.48 & - \\
$\quad$ Proportion of green area within 200m of river & 0.01 & 0.05 & & 0.08 & 0.09 \\
$\quad$ Proportion of urban area within 200m of river & 0.03 & 0.11 & & 0.31 & 0.31 \\
\hline Number of observations & 737 river stretches & & \multicolumn{2}{c}{105 visits } \\
\hline
\end{tabular}

Table 7 shows the estimated river choice model. Only one water quality variable (Bad or Poor river water quality) was significant, i.e. individuals attach significant utility to changes in river water quality from Bad/Poor to Moderate but not from Moderate to Good/High. Individuals also prefer visiting rivers with satisfactory water flow, are highly modified water bodies, and are surrounded by green or urban areas.

Table 7: River choice model

\begin{tabular}{|c|c|c|c|}
\hline Variable & Coefficient & $\begin{array}{c}\text { Standard } \\
\text { error }\end{array}$ & p-value \\
\hline Travel cost & -0.331 & 0.003 & $<0.001^{* * \pi}$ \\
\hline \multicolumn{4}{|l|}{ Water quality } \\
\hline Bad or Poor & -0.500 & 0.050 & $<0.001^{* * * *}$ \\
\hline \multicolumn{4}{|l|}{ Site characteristics } \\
\hline Flow test: fail & -0.859 & 0.566 & $<0.001^{* * * *}$ \\
\hline Highly modified water body & 0.720 & 0.026 & $<0.001^{* * * *}$ \\
\hline Proportion of area within $200 \mathrm{~m}$ of the river that is green & 2.349 & 0.129 & $<0.001^{* * * *}$ \\
\hline Proportion of area within $200 \mathrm{~m}$ of the river that is urban & 1.557 & 0.046 & $<0.001^{* * * *}$ \\
\hline \multicolumn{4}{|l|}{ Sites with missing information } \\
\hline Sites with no location or not matched & 3.141 & 0.024 & $<0.001^{* * * *}$ \\
\hline Site not visited as the main site in the trip & 5.045 & 0.023 & $<0.001^{* * * *}$ \\
\hline Number of participants & & 1,727 & \\
\hline Number of observations & & $1,276,253$ & \\
\hline Pseudo $\mathbf{R}^{2}$ & & 0.892 & \\
\hline
\end{tabular}

Notes: Significance levels: ${ }^{* * * *} 0.1 \%$. Omitted categories: high, good, or moderate water quality; flow test=pass; not highly modified water body.

The are not many clear patterns in the distribution of inclusive values (Figure 4), which is explained by the fact that rivers are dispersed throughout the country. However, there is a cluster of high inclusive values in the southeast, around Cardiff (the capital and largest city of Wales). This might be explained by better accessibility by road to all the rivers in the country 
and to the higher proportion of urban areas surrounding the rivers, rather than by differences in local river water quality.

Figure 4: Rivers: inclusive values

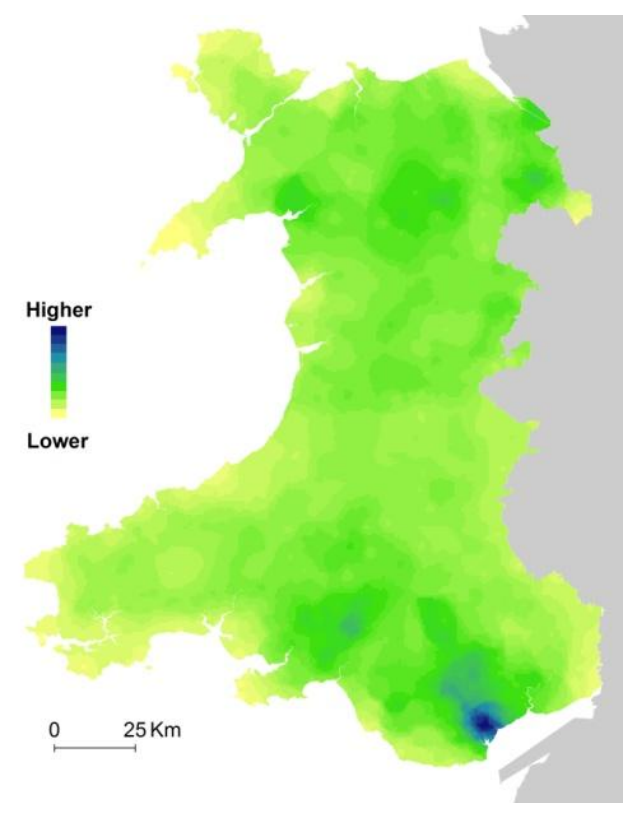

\subsection{Participation model}

Table 8 presents descriptive statistics of the explanatory variables of the participation model. The table only shows statistics for the participant characteristics that were not in Table 4 (participation model for visits to beaches). The statistics for other participant characteristics included in the participation model for visits to rivers are identical to the ones presented in Table 4.

Table 8: Rivers: participation model variables

\begin{tabular}{lccc}
\hline & \multicolumn{2}{c}{ Sample } & \multirow{2}{*}{ Population } \\
\cline { 2 - 3 } & Mean & $\begin{array}{c}\text { Standard } \\
\text { Deviation }\end{array}$ & \\
\hline Number of visits & 4.860 & 11.949 & - \\
Number of visits=0 & 0.687 & - & - \\
\hline $\begin{array}{l}\text { Inclusive value } \\
\quad \text { Value }\end{array}$ & 5.237 & 0.031 & - \\
$\quad$ Value=missing & 0.033 & - & - \\
$\quad$ Participant characteristics & & & \\
$\quad$ Full-time work & 0.398 & - & 0.420 \\
$\quad$ High environmental concern & 0.188 & - & - \\
\hline
\end{tabular}

Note: $\mathrm{N}=5,995$. High environmental concern: answer 5 (in a scale 1-5) to question about concern for changes to biodiversity in Wales. 
Table 9 shows the estimated model. As expected, people with higher inclusive value make more trips. However, the variable was not significant at the $10 \%$ level. Individuals who live in rural areas, do not have a disability, are not in full-time work, and who own a dog also make more trips. Individuals with lower inclusive value and those who are aged above 75 , live in town fringes, have low qualifications, have a disability, do not own a dog, and did not state high environmental concern, have a higher probability of making no trips to a river over a month. The dispersion parameter is significant.

Table 9: Rivers: participation model

\begin{tabular}{|c|c|c|c|c|}
\hline & Coefficient & $\begin{array}{c}\text { Standard } \\
\text { error }\end{array}$ & p-value & \\
\hline \multicolumn{5}{|l|}{ Number of visits } \\
\hline \multicolumn{5}{|l|}{ Inclusive value } \\
\hline Value & 0.247 & 1.217 & 0.839 & \\
\hline Missing value & 1.823 & 6.388 & 0.775 & \\
\hline \multicolumn{5}{|l|}{ Participant characteristics } \\
\hline Type of area: rural & 0.190 & 0.939 & 0.043 & *** \\
\hline Have a limiting disability & -0.224 & 0.103 & 0.029 & *** \\
\hline Full-time work & -0.151 & 0.074 & 0.041 & \\
\hline Owns a dog & 0.408 & 0.074 & $<0.001$ & \\
\hline Constant & 1.234 & 6.392 & 0.847 & \\
\hline \multicolumn{5}{|l|}{ Probability of zero visits } \\
\hline \multicolumn{5}{|l|}{ Inclusive value } \\
\hline Value & -6.429 & 1.482 & $<0.001$ & ****** \\
\hline Missing value & -33.629 & 7.769 & $<0.001$ & \\
\hline \multicolumn{5}{|l|}{ Participant characteristics } \\
\hline Age: $>75$ & 0.742 & 0.193 & $<0.001$ & "***** \\
\hline Type of area: town fringe & -0.254 & 0.112 & 0.024 & ${ }^{* * *}$ \\
\hline Qualifications: low & 0.283 & 0.151 & 0.061 & \\
\hline Have a limiting disability & 0.463 & 0.123 & $<0.001$ & *** \\
\hline Owns a dog & -0.330 & 0.094 & $<0.001$ & ***** \\
\hline High environmental concern & -0.359 & 0.144 & 0.013 & \\
\hline Constant & 34.402 & 7.77 & $<0.001$ & \\
\hline Dispersion parameter & 0.906 & 0.063 & 0.057 & \\
\hline Number of observations & & 5,995 & & \\
\hline Number of zero observations & & 4,180 & & \\
\hline
\end{tabular}

Notes: Significance levels: ${ }^{*} 10 \%,{ }^{* *} 5 \%,{ }^{* * *} 1 \%,{ }^{* * * *} 0.1 \%$. Omitted categoriesage $<75 ;$ : urban areas; high or medium qualifications; no limiting disability; not in full-time work; do not own a dog; do not have high environmental concern.

\subsection{Value}

Table 10 shows the value of changes in water quality and other river characteristics for existing visits and its $95 \%$ confidence interval, the average impact on the number of visits, and the average value for all visits (existing and new).

Improvements in water quality above bad/poor in a given river stretch have a value of $£ 1.51$ for existing visits and lead, on average, to a $65 \%$ increase in the number of visits to that river 
stretch. The average value for all visits (existing and new) is $£ 2.00$ (as a ratio of existing visits). This represents a total value of $£ 23,913$ per month. Improvements in water flow have a bigger impact on number of visits (165\%) and value (£4.73/existing visit and $£ 103,701 /$ month in total). An increase in $1 \%$ in the proportion of green areas around the river stretch would increase number of visits in $2 \%$ and have a value of $£ 0.72 /$ existing visit and $£ 11,939 /$ month in total.

Table 10: Value and impact on visits of improvements in water quality and other river characteristics

\begin{tabular}{|c|c|c|c|c|c|}
\hline \multirow{2}{*}{$\begin{array}{l}\text { Type of improvement } \\
\text { Type of change }\end{array}$} & \multirow{2}{*}{\multicolumn{2}{|c|}{$\begin{array}{c}\text { In an } \\
\text { unspecified river } \\
\text { Value for } \\
\text { existing visits }\end{array}$}} & \multicolumn{3}{|c|}{$\begin{array}{c}\text { Separate improvements } \\
\text { in each river }\end{array}$} \\
\hline & & & $\begin{array}{l}\text { Average change } \\
\text { in visits }\end{array}$ & $\begin{array}{r}\text { Averag } \\
\text { for existing : }\end{array}$ & $\begin{array}{l}\text { alue, } \\
\text { new visits }\end{array}$ \\
\hline Unit & $\begin{array}{r}\text { Per } \mathrm{G} \\
(\mathrm{C} \\
\text { confic }\end{array}$ & $\begin{array}{l}\text { isting visit } \\
\text { ntral and } \\
\text { nce interval) }\end{array}$ & $\%$ & $\begin{array}{l}\text { Per existing } \\
\text { visit }\end{array}$ & $\begin{array}{l}\text { Per } \\
\text { month }\end{array}$ \\
\hline \multicolumn{6}{|l|}{ Water quality } \\
\hline $\mathrm{Bad} /$ Poor $\rightarrow \mathrm{No}$ & $£ 1.51$ & $(1.21-1.80)$ & $65 \%$ & $£ 2.00$ & $£ 23,913$ \\
\hline \multicolumn{6}{|l|}{ Other site characteristics } \\
\hline Flow: Fail $\rightarrow$ Pass & $£ 2.59$ & $(2.25-2.93)$ & $165 \%$ & $£ 4.73$ & $£ 103,701$ \\
\hline$+1 \%$ green within $200 \mathrm{~m}$ & $£ 0.07$ & $(0.06-0.08)$ & $2 \%$ & $£ 0.72$ & $£ 11,939$ \\
\hline
\end{tabular}

Figure 5 shows the shows the average value per month of separate improvements in each river stretch to achieve water status above bad/poor, i.e. the values in the last column of Table 10. The values are higher in the southeast part of the country.

Figure 5: Value of improvements to rivers (£/month)

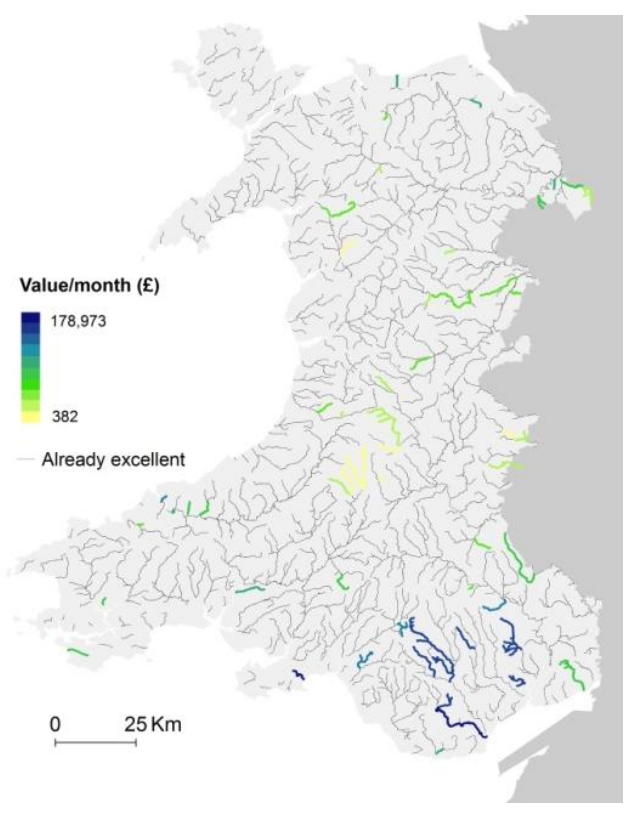




\section{Discussion}

The methods used in this paper rely on some assumptions and have some caveats, which we discuss in this section.

Our indicators of the number of outdoor visits may overestimate the actual number of visits to beaches and rivers, as participants who visited a beach/river in the last outdoor visit did not necessarily visit a beach/river in all outdoor visits made in the last month. On the other hand, participants who did not visit a beach/river in the last visit may have visited one in a previous visit. Not accounting for this may underestimate the number of visits. The assumption is that our indicators balance these conflicting factors and produce a reasonable approximation of the true number of visits.

Many visits could not be matched to known beaches and rivers in Wales, and so they could not be analysed in relation to site characteristics. This can be explained by poor accuracy of the locations of some visits, as indicated by WORS participants. Participants may also have wrongly classified a site as a beach (for example when the location stated is inland) or meant to identify a sea or coastline feature, rather than a beach (as those two types of features were provided in the same answer as beach, in the WORS questionnaire). The existence of unmatched visits is a limitation. However, the estimated models were robust enough to provide information on the significant variables affecting site choice, and on the association between the utility derived from the choice set and the number of visits to beaches and rivers. In addition, as shown in Table A2 in Appendix, there are no major differences between the characteristics of participants with matched and unmatched locations. As such, we are confident that the models are representative of the behaviour of Welsh residents who visited beaches and rivers.

Due to the lack of data, the models did not include variables on hard-to-measure aspects that might explain site choice, for example the aesthetic appeal of the sites, seclusion, and remoteness. However, there is no reason to believe that these aspects are correlated with water quality, and so we are confident that the influence of water quality on site choice is not due to confounding factors. The WORS data also had no survey date, which could be used to account for the effect of seasonality in the number of visits to beaches and rivers. Furthermore, we had no information on the real number of visits to each beach/river, preventing the calibration of the model predictions.

We also made assumptions regarding the cut-off distances in the GIS analyses. The cut-off distance to identify matched beaches and rivers was $800 \mathrm{~m}$. Using a shorter distance $(400 \mathrm{~m})$ 
would imply dropping $44 \%$ of the visits to beaches and $19 \%$ of the visits to rivers. Using a longer distance $(1000 \mathrm{~m})$ would only lead to an increase of $7 \%$ and $13 \%$ of visits to beaches and rivers, respectively. In the calculation of the spatial variables measuring the area around rivers, we used a radius of $200 \mathrm{~m}$. The use of other values $(100 \mathrm{~m}$ and $400 \mathrm{~m})$ resulted in variables that were insignificant in the river choice model.

The model specification also assumed that participants are aware of the characteristics of all beaches/rivers and that site choice is not influenced by habit or by previous experiences. In other words, there is no relationship between the choices of the same individuals on different occasions. The use of a conditional logit specification for the site choice model also assumes that all individuals have the same preferences and that the choice between two options is not affected by the introduction or removal of other options. It was computationally infeasible to estimate a model that relaxes this assumption (e.g. a mixed logit model). Nevertheless, the estimated models were in line with prior expectations, i.e., individuals prefer sites that had better water quality and were cheaper to access, and make more trips when the utility of the available sites is higher.

Finally, there are also limitations of using a revealed preference method. The values may be underestimated because the method does not capture any non-use value (e.g. the value of the site beyond its use for recreation). The method is also sensitive to correlations between attributes (in this case, water quality and travel cost), in contrast with stated preference methods, which can reduce this correlation by producing experimental designs with combinations of attribute levels. The conjunction of revealed preference and stated preference methods could therefore confirm the results obtained in this paper.

\section{Conclusions}

This paper estimated the value of potential improvements in water quality in beaches and rivers in Wales, considering both existing and new visits. We used data on visits reported in the Welsh Outdoor Recreation Survey, adapting an existing revealed preference method that accounts for both the value accrued to existing visits and generated by new trips. We added to the literature by: 1) valuing both beach and river water quality, for all recreational uses, and 2) estimating values at the national level, aggregated for the whole population of Wales, and mapped to show the areas where potential benefits of improving water quality are higher

We found that improving water quality of a beach from good to excellent has a value of $£ 3.42 /$ visit for existing visits and leads to an average increase in $54 \%$ in the number of visits 
to that beach, resulting in an overall value of $£ 269,445$ per month. The highest values are in the beaches near Swansea in the south coast. Improving water quality of a beach from sufficient/poor to good, or adding an extra beach facility or activity have a much smaller value and impact on number of visits. Improving water quality of a river stretch to above bad/poor has a value of $£ 1.51 /$ visit for existing visits and leads to an increase in $65 \%$ in the number of visits to that river stretch, resulting in an overall average value of $£ 23,913$ per month. The highest values and in the south east part of Wales. Improving water flow has a higher value and impact on number of visits. Increasing green spaces in $1 \%$ in the area around the river has a smaller value and impact.

The paper also identified the parts of the country that are currently better served in terms of better (i.e. cheaper) access to beaches and rivers with better water quality. This is shown in the maps of the inclusive values that were derived from the site choice models, as those values are indicators of the utility that an individual living in a given location can derive from the set of all beaches/rivers in the country, taking into account both the quality of those beaches/rivers and travel costs to acess them. We found that the southwest part of the country has the best access to beaches with better quality but the southeast part (the area around Cardiff) has the best access to rivers with better quality.

Notwithstanding the caveats discussed in the previous section, the study produced estimates based on real-world behaviour and so it can be useful for planning and management purposes. For example, the results can be integrated in decision-supporting tools that allow users to specify bespoke scenarios with respect to changes in water quality for a specific beach or river and predict the change in the number of visits to that beach or river and the value for existing and new visits.

\section{Acknowledgments}

Removed from submitted version

\section{References}

Abu-Hilal, A H., Khordagui, H K. (2007) Assessment of tar pollution on the United Arab Emirates beaches. Environment International 19, 589-596.

Almeida, C A., Quintar, S., González, P., Malela, M A. (2007) Influence of urbanization and tourist activities on the water quality of the Potrero de los Funes River (San Luis - Argentina). Environmental Monitoring and Assessment 133, 459-465. 
Anciaes, P., Metcalfe, P J., Sen, A. (2020). A combined SP-RP model to estimate the value of improvements in freshwater angling in England. Journal of Environmental Economics and Policy 9, 167-187.

Arheimer, B., Andréasson, J., Fogelberg, S., Johnsson, H., Pers, C B., Persson, K. (2005) Climate change impact on water quality: model results from Southern Sweden. Ambio 34, 559-566.

Artell, J. (2014) Lots of value? A spatial hedonic approach to water quality valuation. Journal of Environmental Planning and Management 57, 862-882.

Beharry-Borg, N., Scarpa, R. (2010) Valuing quality changes in Caribbean coastal waters for heterogeneous beach visitors. Ecological Economics 69, 1124-1139.

Bell, S., Tyrväinen, L., Sievänen, T., Pröbstl, U., Simpson, M. (2007) Outdoor recreation and nature tourism: a European perspective. Living Reviews in Landscape Research 1:2.

Bockstael, N E., Hanemann, W M., Kling, C L. (1987) Estimating the value of water quality improvements in a recreational demand framework. Water Resources Research 23, 951-960.

Bockstael, N., McConnell, K., Strand, I. (1989) Measuring the benefits of improvements in water quality: the Chesapeake Bay. Marine Resource Economics 6, 1-18.

Brouwer, R., Bliem, M., Getzner, M., Kerekes, S., Milton, S., Palarie, T., Szerényi, Z., Vadineanu, A., Wagtendonk, A. (2016) Valuation and transferability of the non-market benefits of river restoration in the Danube river basin using a choice experiment. Ecological Engineering 87, 20-29.

Carson R, Mitchell R C. (1993) The value of clean water: the public's willingness to pay for boatable, fishable, and swimmable quality water. Water Resources Research 9, 2445-54.

Derraik, J G B. (2002) The pollution of the marine environment by plastic debris: a review. Marine Pollution Bulletin 44, 842-852.

DFT (Department for Transport) (2015a) Provision of Market Research for Value of Travel Time Savings and Reliability. Non-technical Summary Report., https://www.gov.uk/government/publications/valuesof-travel-time-savings-and-reliability-final-reports

DFT (Department for Transport) (2015b) Free Flow Vehicle Speed Statistics in Great Britain: 2015 report., https://www.gov.uk/government/statistics/free-flow-vehicle-speeds-in-great-britain-2015

EFTEC (Economics for the Environment Consultancy) (2002) Valuation of Benefits to England and Wales of a Revised Bathing Water Quality Directive and Other Beach Characteristics Using the Choice Experiment Methodology. Report to UK Department for Environment, Food and Rural Affairs., https://ukbeachmanagementforum.files.wordpress.com/2014/03/defra-beach-user-study-2002.pdf

Eggert, H., Olsson, B. (2009) Valuing multi-attribute marine water quality. Marine Policy 33, 201-206.

EP/EC (European Parliament and European Council) (2000) Directive 2000/60/EC of the European Parliament and of the Council of 23 October 2000 establishing a framework for Community action in the field of water policy. Official Journal L 327. 22 December 2000., https://eur-lex.europa.eu/legalcontent/EN/TXT/?uri=CELEX:02000L0060-20141120 
Georgiou, S., Langford, I H., Bateman, I J., Turner, R K. (1998) Determinants of individuals' willingness to pay for perceived reductions in environmental health risks: a case study of bathing water quality. Environment and Planning A: Economy and Space 30, 577-594.

Glenk, L., Lago, M., Moran, D. (2011) Public preferences for water quality improvements: implications for the implementation of the EC Water Framework Directive in Scotland. Water Policy 13, 645-662.

Green, C H., Tunstall, S M. (1991) The evaluation of river water quality improvements by the contingent valuation method. Applied Economics 23, 1135-1146.

Hanley, N., Bell, D., Alvarez-Farizo, B. (2003) Valuing the benefits of coastal water quality improvements using contingent and real behaviour. Environmental and Resource Economics 24, 273-285.

Hanley, N., Wright, R E., Alvarez-Farizo, B. (2006) Estimating the economic value of improvements in river ecology using choice experiments: an application to the water framework directive. Journal of Environmental Management 78, 183-193.

Hjerppe, T., Seppälä, E., Väisänen, S., Marttunen, M. (2017) Monetary assessment of the recreational benefits of improved water quality - description of a new model and a case study. Journal of Environmental Planning and Management 60, 1944-1966.

Huhtala, A., Lankia, T. (2012) Valuation of trips to second homes: do environmental attributes matter? Journal of Environmental Planning and Management 55, 733-752.

Hynes, S., Tinch, D., Hanley, N. (2013) Valuing improvements to coastal waters using choice experiments: an application to revisions of the EU Bathing Waters Directive. Marine Policy 40, 137-144.

Jensen, C R., Guthrie, S P. (2006) Outdoor Recreation in America (6th Edition). Human Kinetics, Champaign.

Krinsky I., Robb A L. (1986) On approximating the statistical properties of elasticities. Review of Economics and Statistics 68, 715-719.

Johnstone, C., Markandya, A. (2006) Valuing river characteristics using combined site choice and participation travel cost models. Journal of Environmental Management 80, 237-247.

Lankia, T., Neuvonen, M., Pouta, E. (2019) Effects of water quality changes on the recreation benefits of swimming in Finland: Combined travel cost and contingent behavior model. Water Resources and Economics 25, 2-12.

Leggett, C., Bockstael, N. (2000) Evidence of the effects of water quality on residential land prices. Journal of Environmental Economics and Management 39, 121-144.

Lew, D L., Larson, D M. (2005) Valuing Recreation and Amenities at San Diego County Beaches. Journal of Coastal Management 33, 71-86.

Loomis J. (2002) Quantifying recreation use values from removing dams and restoring free-flowing rivers: a contingent behavior travel cost demand model for the Lower Snake River. Water Resources Research 38, $2 / 1-2 / 8$.

Machado, F S., Mourato, S. (2002) Evaluating the multiple benefits of marine water quality improvements: how important are health risk reductions? Journal of Environmental Management 65, 239.250. 
Magat, W A., Huber, J., Viscusi, W K. (2000) An iterative choice approach to valuing clean lakes, rivers, and streams. Journal of Risk and Uncertainty 21, 7-43.

McFadden, D. (1978) Modelling the choice of residential location., in A Karlqvist, L Lundqvist, F Snickars, and J Weibull (Eds.) Spatial Interaction and Planning Models. North Holland, Amsterdam., pp. 75-96.

Meyerhoff, J., Dehnhardt, A., Hartje, V. (2010) Take your swim suit along... - The value of improving urban bathing sites in the metropolitan area of Berlin. Journal of Environmental Planning and Management 53, 107-124.

Morrisson, M., Bennett, J. (2004) Valuing New South Wales rivers for use in benefit transfer. Australian Journal of Agricultural and Resource Economics 48, 591-611.

Mosley, L M. (2015) Drought impacts on the water quality of freshwater systems: review and integration. Earth-Science Reviews 140, 203-214.

Murdoch, P S., Baron, J S., Miller, T L. (2000) Potential effects of climate change on surface-water quality in North America. Journal of the American Water Resources Association 36, 347-366.

NRW (Natural Resources Wales/Cyfoeth Naturiol Cymru) (2013) Diffuse Water Pollution in Wales - Issues, Solutions and Engagement for Action. NRW, https://cdn.naturalresources.wales/media/4059/diffusewater-pollution-in-wales.pdf?mode $=$ pad\&rnd $=131596369370000000$

NRW (Natural Resources Wales/Cyfoeth Naturiol Cymru) (2015) Wales Outdoor Recreation Survey 2014: Final Report. NRW, https://cdn.naturalresources.wales/media/4757/wales-outdoor-recreation-survey2014-final-report.pdf? mode $=$ pad\&rnd $=131456374980000000$

Ouyang, T., Zhu, Z., Kuang, Y. (2006) Assessing impact of urbanization on river water quality in the Pearl River Delta Economic Zone, China. Environmental Monitoring and Assessment 120, 313-325.

Pakalniete, K., Aigars, J., Czajkowski, M., Strake, S., Zawojska, E., Hanley, N. (2017) Understanding the distribution of economic benefits from improving coastal and marine ecosystems. Science of the Total Environment 584/585, 29-40.

Penn, J., Hu, W., Cox, L., Kozloff, L. (2015) Values for recreational beach quality in Oahu, Hawaii. Marine Resource Economics 31, 47-62.

Perni, A., Martinez-Paz., Martínez-Carrasco, D. (2002) Social preferences and economic valuation for water quality and river restoration: the Segura River, Spain. Water and Environment Journal 26, 274284.

Poor, J., Pessagno, K., Paul, R. (2007) Exploring the hedonic value of ambient water quality: a local watershed-based study. Ecological Economics 60, 797-806.

Quevauviller, P., Borchers, U., Thompson, K C., Simonart, T. (Eds). (2008) The Water Framework Directive - Ecological and Chemical Status Monitoring. Wiley, Chichester.

Small, K., Rosen, H. (1981) Applied welfare economics of discrete choice models. Econometrica 49, 105130.

Söderqvist, T. (1998) Why give up money for the Baltic Sea? Motives for people's willingness (or reluctance) to pay. Environmental and Resources Economics 12, 249-254. 
Toimil, A., Díaz-Simal, P., Losada, I J., Camus, P. (2018) Estimating the risk of loss of beach recreation value under climate change. Tourism Management 68, 387-400.

Torres-Bejarano, F., González-Márquez, L C., Díaz-Solano, B., Torregroza-Espinosa, A C., CanteroRodelo, R. (2018) Effects of beach tourists on bathing water and sand quality at Puerto Velero, Colombia. Environment, Development and Sustainability 20, 255-269.

Tudor, D T., Williams, A T. (2006) A rationale for beach selection by the public on the coast of Wales, UK. Area 38, 153-164.

Vesterinen, J., Pouta, E., Huhtala, A., Neuvonen, M. (2010) Impacts of changes in water quality on recreation behavior and benefits in Finland. Journal of Environmental Management 91, 984-994.

Williams, H. (1977) On the formation of travel demand models and economic evaluation measures of user benefits. Environment and Planning A 9, 285-344.

\section{Appendix}

Table A.1: Beach characteristics

Facilities $\quad$ Campsite; food; litter bins; shops; slipway; toilets Amusements; boat trips; bowling; children's rides; country park; crazy golf; dunes; funfair; gardens; golf; information centre; leisure centre; lighthouse; museum;

Beach features nature reserve; nature trails; pier; promenade; Royal Society for the Protection of Birds reserve; rock pools; sea-life centre; sports centre; tourist information; visitor centre; yacht club

Sea life Dolphins; otters; porpoises; seals

Bird watching; boating; canoeing; climbing; cycling; donkey rides; fishing; fossil

Activities hunting; horse riding; jet-skiing; kayaking; power boating; rock pooling; sailing; scuba diving; snorkelling; sunbathing; surfing; swimming; walking; waterskiing; water sports; windsurfing; yachting 
Table A2: Characteristics of WORS participants: matched vs. unmatched visits (\%)

\begin{tabular}{lcccc}
\hline & \multicolumn{2}{c}{$\begin{array}{c}\text { Participants with } \\
\text { matched visits }\end{array}$} & \multicolumn{2}{c}{$\begin{array}{c}\text { Participants with } \\
\text { unmatched visits }\end{array}$} \\
\cline { 2 - 5 } Age & Beaches & Rivers & Beaches & Rivers \\
16-24 & 12.5 & 16.0 & 8.0 & 9.8 \\
$25-44$ & 36.7 & 36.2 & 30.6 & 33.6 \\
$45-64$ & 33.6 & 32.6 & 40.3 & 37.3 \\
$65-74$ & 10.5 & 12.9 & 12.5 & 12.0 \\
$>$ 75 & 6.7 & 2.3 & 8.7 & 7.4 \\
\hline Type of area & & & & \\
Urban & 59.0 & 68.4 & 66.6 & 60.7 \\
Town fringe & 23.3 & 21.1 & 16.3 & 19.1 \\
Rural & 17.0 & 10.2 & 16.6 & 19.7 \\
\hline Qualifications & & & & \\
High qualifications & 31.2 & 19.8 & 35.1 & 33.1 \\
Medium qualifications & 61.9 & 70.6 & 55.0 & 57.8 \\
Low qualifications & 6.9 & 9.5 & 9.9 & 9.1 \\
\hline Other & & & & \\
In full-time work & 46.4 & 37.6 & 40.8 & 45.4 \\
Illness or disability limiting activities & 14.8 & 16.0 & 23.1 & 17.1 \\
Carer & 23.1 & 28.9 & 28.6 & 22.6 \\
Have access to a car/van & 88.4 & 89.2 & 88.7 & 89.6 \\
Owns/care for a dog & 40.1 & 59.0 & 37.2 & 37.0 \\
High environmental concern & 24.6 & 8.5 & 20.5 & 19.5 \\
\hline
\end{tabular}

